\title{
Optimization of industrial machine maintenance scheduling using ant colony method
}

\author{
Iwan Aang Soenandi ${ }^{1, *}$ and Teuku Emily Budiman ${ }^{1}$ \\ ${ }^{1}$ Department of Industrial Engineering, Faculty of Engineering \& Computer Science, Krida Wacana \\ Christian University, 11440 Jakarta, Indonesia
}

\begin{abstract}
The importance of machine maintenance has been gradually recognized especially with the great attention in industrial sector. A company was named $\mathrm{M}$ is a manufacturing company which engaged in the industrial manufacturer of body pail cans. Previously, the process of machine maintenance at company $\mathrm{M}$ is to repair the machine when a problem occurs. This causes several machines to break down frequently and disrupt the production process. Furthermore, the purpose of this research is to determine the optimum and well-planned maintenance scheduling that can reduce the risk of- or prevent machine failures that may ruin the production process by doing the preventive maintenance in right time. Ant Colony Optimization (ACO) method was used in this research as maximizing the interval time between preventive maintenance periods before the trouble occurs based on previous breakdown data period as minimizing frequency of the task. In the principle of $\mathrm{ACO}$, the required parameters are $\alpha, \beta, \mathrm{m}, \mathrm{e}$, el. As a result of using ACO with the combination of parameters above, the optimal well-planned maintenance scheduling was obtained by using $\alpha=2, \beta=5, \mathrm{e}=0.3$, el $=0.96$, and a number of ants needed. Finally, the optimizing of schedule maintenance has proposed in daily for next year period.
\end{abstract}

\section{Introduction}

The maintenance of machines is an essential process to support the production. Poor maintenance causes the decrease of economic life and leads to declining production capacity and loss for the company. Hence, it is a necessary process to keep the functional aspect of the machine as research from Sharma and Yadava [1]. We found from another researcher [2] explained that there are 3 types of maintenance: preventive, corrective and predictive. Preventive maintenance has selected in this research because it's consists of a set of activities that aim at improving the overall reliability and availability of a system[3] are conducted in a routine, planned and scheduled manner. Predictive maintenance was chosen because it could detect failure accurately when the operation is undergoing. The aim of predictive maintenance scheduling is to determine the optimal frequency of maintenance based on Arab et al.[4] research.

\footnotetext{
* Corresponding author: iwan.as@ukrida.ac.id
} 
The scheduling of maintenance is imperative for the company to maintain the lifespan of the machine and prevent further breakdown. As expressed by Liu and Lv [5] maintenance plays a very important role to utilize the machine effectively in the aspects of cost, safety, and product availability. In this research exposed that the scheduling in a manufacturing system is a very interesting and challenging, especially in the case of high complexity; it requires accurate alternatives as scheduling is a vital key to improve the productivity of the whole system. Thus, to plan the maintenance schedule accurately using ACO as in the research by Samrout et al. [6], this method showed a better result in term of stability. Due to its stability in searching for optimum result, ACO is widely used in solving real-world-engineering issues [7]. ACO has also perceived a result in optimum solution because the search result aims to the maximum of objective function needed [8]. Moreover, the scarce use of ACO method in real case reflected a huge interest in this choice of method.

The aim of this research is to determine the optimum schedule of preventive maintenance so that it may reduce the risk of- or prevent machine failure that will ruin the production process, as the objective function is maximize the maintenance interval time that obtained the lowest frequency for doing maintenance by the technician. Our method is based on a modified ACO algorithm that applied for maximizing, and we will show this algorithm has an efficient answer for this optimization problem [9].

\section{Experimental Details}

In this research, for the problem description on maintenance schedule as we described in introduction, we modelled the problem to find an optimal sequence for preventive maintenance using ACO algorithm. In our application, each node represents an interval time of machine before breakdown or trouble time. To find the optimum schedule of preventive maintenance must do, we used quantitative data. This research is perceived as quantitative since it based on measurable data to achieve a strong, valid quantitative interpretation. Based on the purpose, this research used a descriptive method that investigating the status of a group of population, objects, a set of condition, a systematic idea or a class of occasion in the present time from Vasko et al. [10]. From direct observation, we could see and understand the real-time condition of the subject. By interview method, we could gain the information of machine condition and history, the type of machines, the type of failures and particularly the data of machine failure in 2016. All this data was used to find the optimization of scheduled maintenance.

ACO method is based on ants' behaviour to find the most optimum route from the anthill to the source of food. In the principle of ACO, the required parameters are $\alpha, \beta, \mathrm{m}, \mathrm{e}$, el. By using ACO with the combination of parameters above and execute it with Matlab 2013 b licensed version from Mathworks leads the convergence towards an optimal solution of the problem [11], doing the maintenance task with acceptable time and technician, and finally obtained the optimal well-planned maintenance scheduling for one year period.

This model has some assumptions as only those trouble listed that must and can be maintained, there are 2 or 3 technicians to do the preventive maintenance task, the task is not done simultaneously on one machine and the available working days are 5 days in Monday to Friday and the maximum of maintenance time was 1 hour.

\section{Results and Discussion}

In this company, there were 8 machines which were used to produce the body of pail cans are slitter, cutting, rolling, welder, expander, flanger, seamer and laspand machines. After 
we analysed all the machine problems in that company with Pareto diagram, we determined the main problems of maintenance schedule and defined on five matrices. In this research, the model of production scheduling based on the machine used was a flow shop model; in which each job had an identical flow pattern (linear) and each machine had a target of capacity as 2000 units/days.

\subsection{Matrix}

Here we present the matrix used as the input in MATLAB software, which is nodes in square-grid matrix forms of $17 \times 17,16 \times 16,4 \times 4,19 \times 19$ and $8 \times 8$. The history of trouble in each machine in interval time of operational hour was represented by matrix W1 (17x17) for trouble at welding roll in Table 1, matrix W2 (16x16) for breaking of copper line in Table 2, and matrix W3 $(4 \times 4)$ for trouble at calibration instrument in Table 3 . The trouble of flanger was represented by matrix F1 (19x19) in Table 4 for unstable motor while unstable of flanger adjustment was represented by matrix F2 (8x8) in Table 5.

Table 1. The value matrices of $\mathrm{W} 1$

\begin{tabular}{|c|c|c|c|c|c|c|c|c|c|c|c|c|c|c|c|c|c|}
\hline & $\mathbf{1}$ & $\mathbf{2}$ & $\mathbf{3}$ & $\mathbf{4}$ & $\mathbf{5}$ & $\mathbf{6}$ & $\mathbf{7}$ & $\mathbf{8}$ & $\mathbf{9}$ & $\mathbf{1 0}$ & $\mathbf{1 1}$ & $\mathbf{1 2}$ & $\mathbf{1 3}$ & $\mathbf{1 4}$ & $\mathbf{1 5}$ & $\mathbf{1 6}$ & $\mathbf{1 7}$ \\
\hline $\mathbf{1}$ & 0 & 18 & $\mathbf{4 1}$ & 61 & 85 & 103 & 119 & 138 & 155 & 194 & 216 & 232 & 250 & 261 & 279 & 299 & 313 \\
\hline $\mathbf{2}$ & 18 & 0 & 23 & 43 & 67 & 85 & 101 & 120 & 137 & 176 & 198 & 214 & 232 & 243 & 261 & 281 & 295 \\
\hline $\mathbf{3}$ & 41 & 23 & 0 & 20 & 44 & 62 & 78 & 97 & 114 & 153 & 175 & 191 & 209 & 220 & 238 & 258 & 272 \\
\hline $\mathbf{4}$ & 61 & 43 & 20 & 0 & 24 & 42 & 58 & 77 & 94 & 133 & 155 & 171 & 189 & 200 & 218 & 238 & 252 \\
\hline $\mathbf{5}$ & 85 & 67 & 44 & 24 & 0 & 18 & 34 & 53 & 70 & 109 & 131 & 147 & 165 & 176 & 194 & 214 & 228 \\
\hline $\mathbf{6}$ & 103 & 85 & 62 & 42 & 18 & 0 & 16 & 35 & 52 & 91 & 113 & 129 & 147 & 158 & 176 & 196 & 210 \\
\hline $\mathbf{7}$ & 119 & 101 & 78 & 58 & 34 & 16 & 0 & 19 & 36 & 75 & 97 & 113 & 131 & 142 & 160 & 180 & 194 \\
\hline $\mathbf{8}$ & 138 & 120 & 97 & 77 & 53 & 35 & 19 & 0 & 17 & 56 & 78 & 94 & 112 & 123 & 141 & 161 & 175 \\
\hline $\mathbf{9}$ & 155 & 137 & 114 & 94 & 70 & 52 & 36 & 17 & 0 & 39 & 61 & 77 & 95 & 106 & 124 & 144 & 158 \\
\hline 10 & 194 & 176 & 153 & 133 & 109 & 91 & 75 & 56 & 39 & 0 & 22 & 38 & 56 & 67 & 85 & 105 & 119 \\
\hline $\mathbf{1 1}$ & 216 & 198 & 175 & 155 & 131 & 113 & 97 & 78 & 61 & 22 & 0 & 16 & 34 & 45 & 63 & 83 & 97 \\
\hline 12 & 232 & 214 & 191 & 171 & 147 & 129 & 113 & 94 & 77 & 38 & 16 & 0 & 18 & 29 & 47 & 67 & 81 \\
\hline $\mathbf{1 3}$ & 250 & 232 & 209 & 189 & 165 & 147 & 131 & 112 & 95 & 56 & 34 & 18 & 0 & 11 & 29 & 49 & 63 \\
\hline 14 & 261 & 243 & 220 & 200 & 176 & 158 & 142 & 123 & 106 & 67 & 45 & 29 & 11 & 0 & 18 & 38 & 52 \\
\hline 15 & 279 & 261 & 238 & 218 & 194 & 176 & 160 & 141 & 124 & 85 & 63 & 47 & 29 & 18 & 0 & 20 & 34 \\
\hline 16 & 299 & 281 & 258 & 238 & 214 & 196 & 180 & 161 & 144 & 105 & 83 & 67 & 49 & 38 & 20 & 0 & 14 \\
\hline 17 & 313 & 295 & 272 & 252 & 228 & 210 & 194 & 175 & 158 & 119 & 97 & 81 & 63 & 52 & 34 & 14 & 0 \\
\hline
\end{tabular}

Table 2. The value matrices of W2

\begin{tabular}{|c|c|c|c|c|c|c|c|c|c|c|c|c|c|c|c|c|}
\hline & $\mathbf{1}$ & $\mathbf{2}$ & $\mathbf{3}$ & $\mathbf{4}$ & $\mathbf{5}$ & $\mathbf{6}$ & $\mathbf{7}$ & $\mathbf{8}$ & $\mathbf{9}$ & $\mathbf{1 0}$ & $\mathbf{1 1}$ & $\mathbf{1 2}$ & $\mathbf{1 3}$ & $\mathbf{1 4}$ & $\mathbf{1 5}$ & $\mathbf{1 6}$ \\
\hline $\mathbf{1}$ & 0 & 18 & 38 & 56 & 84 & 99 & 122 & 134 & 156 & 178 & 207 & 218 & 238 & 259 & 273 & 290 \\
\hline $\mathbf{2}$ & 18 & 0 & 20 & 38 & 66 & 81 & 104 & 116 & 138 & 160 & 189 & 200 & 220 & 241 & 255 & 272 \\
\hline $\mathbf{3}$ & 38 & 20 & 0 & 18 & $\mathbf{4 6}$ & 61 & 84 & 96 & 118 & 140 & 169 & 180 & 200 & 221 & 235 & 252 \\
\hline $\mathbf{4}$ & 56 & 38 & 18 & 0 & 28 & $\mathbf{4 3}$ & 66 & 78 & 100 & 122 & 151 & 162 & 182 & 203 & 217 & 234 \\
\hline $\mathbf{5}$ & 84 & 66 & 46 & 28 & 0 & 15 & 38 & 50 & 72 & 94 & 123 & 134 & 154 & 175 & 189 & 206 \\
\hline $\mathbf{6}$ & 99 & 81 & 61 & 43 & 15 & 0 & 23 & 35 & 57 & 79 & 108 & 119 & 139 & 160 & 174 & 191 \\
\hline $\mathbf{7}$ & 122 & 104 & 84 & 68 & 38 & 23 & 0 & 12 & 34 & 58 & 85 & 96 & 116 & 137 & 151 & 168 \\
\hline $\mathbf{8}$ & 134 & 116 & 96 & 78 & 50 & 35 & 12 & 0 & 22 & 44 & 73 & 84 & 104 & 125 & 139 & 156 \\
\hline $\mathbf{9}$ & 156 & 138 & 118 & 100 & 72 & 57 & 34 & 22 & 0 & 22 & 51 & 62 & 82 & 103 & 117 & 134 \\
\hline 10 & 178 & 160 & 140 & 122 & 94 & 79 & 56 & 44 & 22 & 0 & 29 & 40 & 60 & 81 & 95 & 112 \\
\hline $\mathbf{1 1}$ & 207 & 189 & 169 & 151 & 123 & 108 & 85 & 73 & 51 & 29 & 0 & 11 & 31 & 52 & 66 & 83 \\
\hline $\mathbf{1 2}$ & 218 & 200 & 180 & 162 & 134 & 119 & 96 & 84 & 62 & 40 & 11 & 0 & 20 & 41 & 55 & 72 \\
\hline $\mathbf{1 3}$ & 238 & 220 & 200 & 182 & 154 & 139 & 116 & 104 & 82 & 60 & 31 & 20 & 0 & 21 & 35 & 52 \\
\hline $\mathbf{1 4}$ & 259 & 241 & 221 & 203 & 175 & 160 & 137 & 125 & 103 & 81 & 52 & 41 & 21 & 0 & 14 & 31 \\
\hline $\mathbf{1 5}$ & 273 & 255 & 235 & 217 & 189 & 174 & 151 & 139 & 117 & 95 & 66 & 55 & 35 & 14 & 0 & 17 \\
\hline 16 & 290 & 272 & 252 & 234 & 206 & 191 & 168 & 156 & 134 & 112 & 83 & 72 & 52 & 31 & 17 & 0 \\
\hline
\end{tabular}


Table 3. The value matrices of W3

\begin{tabular}{|l|c|c|c|c|}
\hline & $\mathbf{1}$ & $\mathbf{2}$ & $\mathbf{3}$ & $\mathbf{4}$ \\
\hline $\mathbf{1}$ & 0 & 93 & 199 & 276 \\
\hline $\mathbf{2}$ & 93 & 0 & 106 & 183 \\
\hline $\mathbf{3}$ & 199 & 106 & 0 & 77 \\
\hline $\mathbf{4}$ & 276 & 183 & $\mathbf{7 7}$ & 0 \\
\hline
\end{tabular}

Table 4. The value matrices of F1

\begin{tabular}{|c|c|c|c|c|c|c|c|c|c|c|c|c|c|c|c|c|c|c|c|}
\hline & $\mathbf{1}$ & $\mathbf{2}$ & $\mathbf{3}$ & $\mathbf{4}$ & $\mathbf{5}$ & $\mathbf{6}$ & $\mathbf{7}$ & $\mathbf{8}$ & $\mathbf{9}$ & $\mathbf{1 0}$ & $\mathbf{1 1}$ & $\mathbf{1 2}$ & $\mathbf{1 3}$ & $\mathbf{1 4}$ & $\mathbf{1 5}$ & $\mathbf{1 6}$ & $\mathbf{1 7}$ & $\mathbf{1 8}$ & $\mathbf{1 9}$ \\
\hline $\mathbf{1}$ & 0 & 21 & 36 & 53 & 77 & 93 & 107 & 126 & 143 & 162 & 190 & 214 & 228 & 247 & 252 & 266 & $\mathbf{2 8 8}$ & 308 & 326 \\
\hline $\mathbf{2}$ & 21 & 0 & 15 & 32 & 56 & 72 & 86 & 105 & 122 & 141 & 169 & 193 & 207 & 226 & 231 & 245 & 267 & 287 & 305 \\
\hline $\mathbf{3}$ & 36 & 15 & 0 & 17 & 41 & 57 & 71 & 90 & 107 & 126 & 154 & 178 & 192 & 211 & 216 & 230 & 252 & 272 & 290 \\
\hline $\mathbf{4}$ & 53 & 32 & 17 & 0 & 24 & 40 & 54 & 73 & 90 & 109 & 137 & 161 & 175 & 194 & 199 & 213 & 235 & 255 & 273 \\
\hline $\mathbf{5}$ & 77 & 56 & 41 & 24 & 0 & 16 & 30 & 49 & 66 & 85 & 113 & 137 & 151 & 170 & 175 & 189 & 211 & 231 & 249 \\
\hline $\mathbf{6}$ & 93 & 72 & 57 & 40 & 16 & 0 & 14 & 33 & 50 & 69 & 97 & 121 & 135 & 154 & 159 & 173 & 195 & 215 & 233 \\
\hline $\mathbf{7}$ & 107 & 86 & 71 & 54 & 30 & 14 & 0 & 19 & 36 & 55 & 83 & 107 & 121 & 140 & 145 & 159 & 181 & 201 & 219 \\
\hline $\mathbf{8}$ & 126 & 105 & 90 & 73 & 49 & 33 & 19 & 0 & 17 & 36 & 64 & 88 & 102 & 121 & 126 & 140 & 162 & 182 & 200 \\
\hline $\mathbf{9}$ & 143 & 122 & 107 & 90 & 66 & 50 & 36 & 17 & 0 & 19 & 47 & 71 & 85 & 104 & 109 & 123 & 145 & 165 & 183 \\
\hline $\mathbf{1 0}$ & 162 & 141 & 126 & 109 & 85 & 69 & 55 & 36 & 19 & 0 & 28 & 52 & 66 & 85 & 90 & 104 & 126 & 146 & 164 \\
\hline $\mathbf{1 1}$ & 190 & 169 & 154 & 137 & 113 & 97 & 83 & 64 & 47 & 28 & 0 & 24 & 38 & 57 & 62 & 76 & 98 & 118 & 136 \\
\hline $\mathbf{1 2}$ & 214 & 193 & 178 & 161 & 137 & 121 & 107 & 88 & 71 & 52 & 24 & 0 & 14 & 33 & 38 & 52 & 74 & 94 & 112 \\
\hline $\mathbf{1 3}$ & 228 & 207 & 192 & 175 & 151 & 135 & 121 & 102 & 85 & 66 & 38 & 14 & 0 & 19 & 24 & 38 & 60 & 80 & 98 \\
\hline $\mathbf{1 4}$ & 247 & 226 & 211 & 194 & 170 & 154 & 140 & 121 & 104 & 85 & 57 & 33 & 19 & 0 & 5 & 19 & 41 & 61 & 79 \\
\hline $\mathbf{1 5}$ & 252 & 231 & 216 & 199 & 175 & 159 & 145 & 126 & 109 & 90 & 62 & 38 & 24 & 5 & 0 & 14 & 36 & 56 & 74 \\
\hline $\mathbf{1 6}$ & 266 & 245 & 230 & 213 & 189 & 173 & 159 & 140 & 123 & 104 & 76 & 52 & 38 & 19 & 14 & 0 & 22 & 42 & 60 \\
\hline $\mathbf{1 7}$ & 288 & 267 & 252 & 235 & 211 & 195 & 181 & 162 & 145 & 126 & 98 & 74 & 60 & 41 & 36 & 22 & 0 & 20 & 38 \\
\hline $\mathbf{1 8}$ & 308 & 287 & 272 & 255 & 231 & 215 & 201 & 182 & 165 & 146 & 118 & 94 & 80 & 61 & 56 & 42 & 20 & 0 & 18 \\
\hline $\mathbf{1 9}$ & 326 & 305 & 290 & 273 & 249 & 233 & 219 & 200 & 183 & 164 & 136 & 112 & 98 & 79 & 74 & 60 & 38 & 18 & 0 \\
\hline
\end{tabular}

Table 5. The value matrices of F2

\begin{tabular}{|c|c|c|c|c|c|c|c|c|}
\hline & $\mathbf{1}$ & $\mathbf{2}$ & $\mathbf{3}$ & $\mathbf{4}$ & $\mathbf{5}$ & $\mathbf{6}$ & $\mathbf{7}$ & $\mathbf{8}$ \\
\hline $\mathbf{1}$ & 0 & 31 & 65 & 144 & 200 & 247 & 280 & 312 \\
\hline $\mathbf{2}$ & 31 & 0 & 34 & 113 & 169 & 216 & 249 & 281 \\
\hline $\mathbf{3}$ & 65 & 34 & 0 & 79 & 135 & 182 & 215 & 247 \\
\hline $\mathbf{4}$ & 144 & 113 & 79 & 0 & 58 & 103 & 136 & 168 \\
\hline $\mathbf{5}$ & 200 & 169 & 135 & 56 & 0 & 47 & 80 & 112 \\
\hline $\mathbf{6}$ & 247 & 216 & 182 & 103 & 47 & 0 & 33 & 65 \\
\hline $\mathbf{7}$ & 280 & 249 & 215 & 136 & 80 & 33 & 0 & 32 \\
\hline $\mathbf{8}$ & 312 & 281 & 247 & 168 & 112 & 65 & 32 & 0 \\
\hline
\end{tabular}

\subsection{Parameter Testing}

Several selections of parameters $\alpha, \beta, \mathrm{m}$ was tested in this research to find the best computational time and result. All the parameters were listed in Table 6 for each case matrix

Table 6. Testing parameters for each matrix

\begin{tabular}{|c|c|c|c|}
\hline Case Matrix & $\alpha$ & $\beta$ & m \\
\hline W3 (4x4) & \multirow{5}{*}{$\begin{array}{c}0,0.5 \\
0.8,1,2\end{array}$} & \multirow{5}{*}{$\begin{array}{c}0,0.5 \\
0.8,1,2, \\
5\end{array}$} & \multirow{2}{*}{$\begin{array}{c}10,50 \\
100\end{array}$} \\
\hline F2 (8x8) & & & \\
\hline W1 (17x17) & & & \multirow{3}{*}{$\begin{array}{c}100,200 \\
300\end{array}$} \\
\hline W2 (16x16) & & & \\
\hline F1 (19x19) & & & \\
\hline
\end{tabular}


For case W3 and F2, we used the numbers of ants were 10, 50 and 100 as the cases were not complicated and if the number of ants used was excessive, it would result in a longer computation time. However, for W1, W2, and F1, the numbers of ants were 100, 200 and 300 as they were complicated cases and if we used fewer numbers of ants, it would require longer iteration time to achieve the optimum point and needed a longer computation time. Despite that, the number of ants did not significantly influence the optimum solution. The optimum solution was more to be influenced by $\alpha$ and $\beta$ and in this case is was obtained with no others solution better with all identical constraints. Thus, it is important to find the combination closest to the optimum solution in each case. The maximum number of iteration was determined at 800 and the replication was 5 times for each optimum solution we obtained. In the parameter test, each case had a different number of the node so that the optimum value was also varying. Therefore, the parameter test was necessarily conducted for each matrix to obtain the combination closest to optimum solution and shows in Table 7.

Table 7. The best results of each parameter

\begin{tabular}{|c|c|c|c|c|c|c|}
\hline Case & $\alpha$ & $\beta$ & $\mathrm{m}$ & Iteration & Results & Computational Time \\
\hline W3(4x4) & 2 & 5 & 10 & 2 & 552 & 0.07 \\
\hline F2(8x8) & 2 & 5 & 50 & 3 & 624 & 0.13 \\
\hline W1(17x17) & 2 & 5 & 200 & 7 & 626 & 0.43 \\
\hline W2(16x16) & 2 & 5 & 200 & 5 & 580 & 0.46 \\
\hline F1(19x19) & 2 & 5 & 300 & 12 & 652 & 0.89 \\
\hline
\end{tabular}

Moreover, to reduce the frequency of maintenance for W2 and F2 maintenance would be conducted on September 12 for 30 minutes while F1 maintenance would be still conducted on September 13 as it needed 1 hour maintenance time. Table 8 presents the proposed plan of maintenance schedule in each case based on the day in 2017 and shows that the scheduling satisfies all of the constraints.

By doing the implementation in the production line, as a result, this research showed more efficient task for the technician and avoided the disruption of production process compared to previously run maintenance plans without scheduled maintenance plan and successful to achieve the target of production as 2000 units/day.

Table 8. Optimized maintenance schedule planning in 2017

\begin{tabular}{|c|c|c|c|c|c|c|c|c|c|c|c|c|c|c|c|c|c|c|c|c|c|c|c|c|c|c|}
\hline \multirow{2}{*}{ Case } & \multicolumn{4}{|c|}{ January } & \multicolumn{4}{|c|}{ February } & \multicolumn{5}{|c|}{ March } & \multicolumn{5}{|c|}{ April } & \multicolumn{4}{|c|}{ May } & \multicolumn{4}{|c|}{ June } \\
\hline & 9 & 10 & 27 & 30 & 10 & 14 & 19 & 20 & 2 & 8 & 13 & 15 & 27 & 5 & 6 & 12 & 20 & 25 & 12 & 15 & 28 & 31 & & 2 & 19 & 20 \\
\hline W1 & $\mathrm{O}$ & & 0 & & & & & C & & & 0 & & & & 7 & & & 0 & 0 & & & 0 & & & 0 & \\
\hline W2 & & 0 & & 0 & & & & & & & & & & O & & & 0 & & & 0 & 0 & & & & 0 & \\
\hline W3 & & 0 & & & & & & & & & & & & & & 0 & & & & & & & & & & \\
\hline F1 & & & & 0 & & 8 & & & & & & & 0 & & & 0 & & 0 & & 0 & & & $\mathrm{O}$ & & & 0 \\
\hline F2 & & 0 & & & & & & & & & & 0 & & & & & & & & & & & & 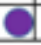 & & \\
\hline
\end{tabular}

\begin{tabular}{|c|c|c|c|c|c|c|c|c|c|c|c|c|c|c|c|c|c|c|c|c|c|c|c|c|}
\hline \multirow{2}{*}{ Case } & \multicolumn{4}{|c|}{ July } & \multicolumn{5}{|c|}{ August } & \multicolumn{5}{|c|}{ September } & \multicolumn{4}{|c|}{ October } & \multicolumn{4}{|c|}{ November } & \multicolumn{2}{|c|}{ December } \\
\hline & 11 & 18 & 27 & 28 & 9 & 11 & 21 & 22 & 25 & 6 & 12 & 13 & 18 & 25 & $2 \mid 6$ & \begin{tabular}{l|l|}
6 & 12 \\
\end{tabular} & 16 & 24 & 2 & 13 & $\mid 17$ & 27 & 4 & \\
\hline W1 & & & & 0 & & & 0 & & & 0 & & & & 0 & & \begin{tabular}{l|l} 
&
\end{tabular} & & 0 & & 0 & & 0 & & \\
\hline W2 & 0 & & & & 0 & & & 0 & & & $\mathrm{O}$ & & & & 0 & & 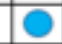 & & 0 & & & & & \\
\hline W3 & & & 0 & & & & & & & & & & & & et & 0 & & & & & & & & \\
\hline F1 & & 0 & & & & 0 & & & 0 & & 0 & & 0 & & 0 & & & 0 & & 0 & & & O & \\
\hline F2 & & & & 0 & & & & & & & & 0 & & & & & 0 & & & & 0 & & & \\
\hline
\end{tabular}




\section{Conclusions}

This work presents a first attempt to seek the optimal preventive maintenance scheduling using ACO algorithm by using the nodes as the interval of trouble time of each machine. Based on the data processing and analysis, this research obtained the best planned and optimum maintenance schedule for one year was obtained by using $\alpha=2, \beta=5, e=0.3$, $\mathrm{el}=0.96$ with several variations of iteration. The maintenance is best conducted in the overtime during Monday-Friday with 2 or 3 technicians for each day and the maximum maintenance time is 1 hour. This result, as applied in production line using this optimum and well-planned maintenance scheduling is reduced the risk of- or prevents machine failures that may ruin the production process.

The result showed more efficient task for the maintenance operation by reducing the number of technician needed, allocating them by exactly date for each maintenance that must run and has avoided the disruption of production process to maintenance plans previously compared. This optimized schedule of maintenance also successful to achieve the target of production as 2000 units/day. As part of the future work in this research topics, the ant colony was recommended to develop for another application for more complex system and another kind of maintenance problems.

\section{References}

1. Sharma and G.S. Yavada, J. Qua. Main. Eng. 17, 5 (2011).

2. B.S. Dhillon, Engineering Maintenance: A Modern Approach. CRC Press LLC, Boca Raton, FL. (2002).

3. S. Soh, N. Radzi, H. Haron, 4th ICCIMS. 310-315. (2012).

4. A. Arab, N. Ismail, L.S. Lee. SSBM. 24, 695. (2012).

5. Q. Liu and W. Lv, Ind Manage Data Syst, 115, 1412. (2015).

6. M.Samrout, R. Kouta, E. Chatelet, N. Chebbo. Reliab. Eng. Syst. Safe. 89, 346. (2005).

7. H.R. Maier, A.R. Simpson, A.C. Zecchin, J. Water Res. Pl. 129, 200. (2003).

8. W.K. Foong, A.R. Simpson, H.R. Maier, S. Stolp. SSBM. 159, 433. (2007).

9. H. Xue, S. Wei, L. Yang. 18th ICIEEM. 1128-1131. (2011).

10. F.J. Vasko, J.D. Bobeck, M.A. Governale, D.J. Rieksts, J.D. Keffer. J. Oper. Res. Soc., 42, 1169-1176. (2011).

11. M. Gravel, W. Price, C. Gagne, Eur J Oper Res, 143, 218-229.(2002). 